\title{
Online assessment, adaptive feedback and the importance of visual learning for students. The advantages, with a few caveats, of using MapleTA
}

DOI:

10.1016/j.iree.2018.03.002

\section{Document Version}

Accepted author manuscript

Link to publication record in Manchester Research Explorer

Citation for published version (APA):

Pezzino, M. (2018). Online assessment, adaptive feedback and the importance of visual learning for students. The advantages, with a few caveats, of using MapleTA. International Review of Economics Education.

https://doi.org/10.1016/j.iree.2018.03.002

Published in:

International Review of Economics Education

\section{Citing this paper}

Please note that where the full-text provided on Manchester Research Explorer is the Author Accepted Manuscript or Proof version this may differ from the final Published version. If citing, it is advised that you check and use the publisher's definitive version.

\section{General rights}

Copyright and moral rights for the publications made accessible in the Research Explorer are retained by the authors and/or other copyright owners and it is a condition of accessing publications that users recognise and abide by the legal requirements associated with these rights.

\section{Takedown policy}

If you believe that this document breaches copyright please refer to the University of Manchester's Takedown Procedures [http://man.ac.uk/04Y6Bo] or contact uml.scholarlycommunications@manchester.ac.uk providing relevant details, so we can investigate your claim.

\section{OPEN ACCESS}




\section{Accepted Manuscript}

Title: Online assessment, adaptive feedback and the importance of visual learning for students. The advantages, with a few caveats, of using MapleTA

Author: Mario Pezzino

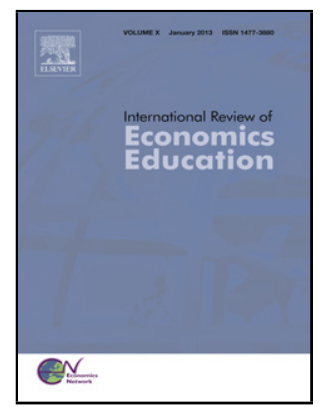

PII:

S1477-3880(17)30041-5

DOI: https://doi.org/doi:10.1016/j.iree.2018.03.002

Reference: IREE 127

To appear in:

Received date: $\quad 27-4-2017$

Revised date: $\quad$ 19-12-2017

Accepted date: $\quad$ 5-3-2018

Please cite this article as: Mario Pezzino, Online assessment, adaptive feedback and the importance of visual learning for students. The advantages, with a few caveats, of using MapleTA, <![CDATA[International Review of Economics Education]]> (2018), https://doi.org/10.1016/j.iree.2018.03.002

This is a PDF file of an unedited manuscript that has been accepted for publication. As a service to our customers we are providing this early version of the manuscript. The manuscript will undergo copyediting, typesetting, and review of the resulting proof before it is published in its final form. Please note that during the production process errors may be discovered which could affect the content, and all legal disclaimers that apply to the journal pertain. 


\title{
Online assessment, adaptive feedback and the importance of visual learning for students. The advantages, with a few caveats, of using MapleTA.*
}

\author{
Mario Pezzino \\ University of Manchester, Oxford Road, Manchester, M13 9PL.
}

April 2017

\begin{abstract}
The paper highlights the importance and necessity of a versatile and reliable platform for online assessment in higher education. Recent technological developments allow instructors to go beyond standard multiple choice questions (MCQs). The paper considers, in particular, two important aspects: (i) embedding visual and interactive material in assignment questions that favours reasoning and learning and (ii) the importance of questions and feedback that can adapt to the particular performance of students. To reinforce the message, the paper shows how the latest release of the platform MapleTA could represent a powerful tool in the hands of educators in those fields where algebraic and diagrammatic analysis is essential to the learning process, such as mathematics, economics and business.
\end{abstract}

Keywords: online assessment; adaptive questions; visual learning; MapleTA.

JEL Classification: A22, C63, D43

*The author is grateful to the editor and two anonymous reviewers for their comments and advice. The author is also grateful to the participants in the Economics Education Seminar Series, UCL, and the 2017 Developments in Economics Education conference for helpful comments and suggestions. Finally, he is grateful to Elsa Lee, eLearning Technologist at the University of Manchester, for her help and patience when the author was taking his first steps with MapleTA. 


\section{Introduction}

The objective of this paper is to point out the importance of two recent developments in online practice and assessment that could allow instructors to move away from standard and repetitive MCQs, significantly improving the learning experience of students. The first innovation is the possibility to create questions that adapt to students' performance; for example, questions that, if answered incorrectly, provide additional questions and hints to induce the student to reach the correct answer using alternative paths. The second development is the use of interactive visual material, such as clickable images and interactive diagrams.

To make our point, we describe the advantages, with a few caveats, of the use of the platform MapleTA. ${ }^{1}$ The platform is built around the mathematical software Maple, allowing the creation of algorithmic questions and analytic manipulation. Of course, it also provides the possibility to create adaptive questions and clickable diagrams.

The use of online resources is a widespread practice in higher education around the world. Instructors share material, organize assessment and provide feedback to students via virtual learning environments. ${ }^{2}$ Similarly, many textbooks provide companion websites that supply online supplementary material, including assessment based on multiple choice quizzes. ${ }^{3}$

Economics instructors have been historically reluctant to consider innovative forms of teaching in favour of a more traditional "chalk and talk" approach. ${ }^{4}$ Nonetheless in the last decade an increasing number of instructors have opted for a blended approach, where innovative use of technology and media has been integrated with more traditional forms of teaching. ${ }^{5}$ The use of media and, in particular, online resources has become, sometimes, a necessity. Indeed, due to the large number of students attending introductory modules, online material (e.g. slides, videoclips, online practice and assessment) often provides a coherent and consistent substitute to personal interaction. Online resources, of course, should not be seen just as a necessity, but they can also be an opportunity to enhance the learning experience of students. In fact, online resources often allow instructors to reconsider the use of time spent in lectures and the way students approach learning outside the classroom. For example, in the context of a flipped classroom, ${ }^{6}$ dry and long mathematical derivations and proofs can be provided via online videos posted on virtual learning environments. This would free time during contact hours to discuss more advanced and engaging material, including real life examples and applications.

Online assessment is a popular form of technological innovation that is

\footnotetext{
${ }^{1}$ http://www.maplesoft.com/products/mapleta/index_personas.aspx

${ }^{2}$ Popular systems adopted in many universities and colleges are, for example, Blackboard (www.blackboard.com) and Moodle (https://moodle.com/).

${ }^{3}$ Olczak (2014) identifies the positive effects of publishers' web-based resources on student learning. Popular learning environments provided by publishers are Pearson's MyEconLab (and new arrival Revel), McGraw Hill's Connect, Cengage's Aplia and Wiley's Wiley Plus.

${ }^{4}$ See, for example, Watts and Schaur (2011).

${ }^{5}$ See, for example, Stephenson and Cortinhas (2013) and Pezzino (2017).

${ }^{6}$ See Lage et al. (2000), Yamarik (2007), Bishop and Verleger (2013) and Roach (2014).
} 
present nowadays in a very large number of economics modules. The key advantage is that, in particular in large classes, online assessment makes it feasible to provide students with immediate feedback on their understanding. Moreover, online practice, based for example on multiple choice questions, can be very useful for students to reinforce their understanding and can be used by instructors as formative and summative assessment.

Standard multiple choice quizzes pose, however, some drawbacks. Questions (and feedback, if available) are standardized. At the same time, students are not incentivized to interact with the material tested in its entirety, but they are essentially asked to identify (often by a process of sequential elimination) the answer that is most likely to be correct. In what follows we shall discuss recent developments in online practice and assessment that will significantly improve the learning experience of students.

Specifically, the remainder of the paper is organised as follows. Section 2 provides a discussion on recent innovations in the provision of online assessment that may prove to be critical in improving the learning experience of students. The platform MapleTA is suggested as a useful example. Section 3 describes the use of adaptive questions. Section 4 provides examples of the use of questions based on visual interaction. Section 5 provides a qualitative evaluation of our experience of the use of MapleTA with year 1 and year 3 UG economics students. Section 6 concludes.

\section{Online assessment innovation as a critical tool for effective learning}

Students, instructors and publishers are increasingly aware of the advantages of using online assessment, in particular tests based on MCQs. Online tests provide very useful practice, especially when accessible multiple times, and help reinforcing classroom-based learning. They can also be used as formal assessment in a module, if the quiz randomly selects questions from a pool. Online assessments, in addition, provide immediate feedback to students.

Thanks to the fact that students can be allowed to practice multiple times similar questions and, at the same time, obtain immediate feedback, the careful use of online assessment can be seen as a critical tool of constructivist teaching. The constructivist theory of learning argues that people learn through exploring new things, making mistakes and reflecting on those experiences. This implies that students can enhance their learning experience if exposed to active techniques (e.g. experiments, real-world problems), especially if they are then asked to reflect on what they are doing (see for example Hoover (1996)). Computer technologies and, in particular, online assessments can be seen as useful tools in constructivist learning (see Chan (2006)). It is essential however that, when interacting with online assessment, students have an interactive experience (gradually building on what they already know) and instructors have an interactive role (helping and guiding students constructing their own knowledge). Because 
of this, the adaptive features of online tests and the use of questions with interactive visual resources, as we are going to describe in this paper, become essential.

Standard online assessment, however, presents a series of problems. Tests based on standard MCQs are unavoidably fixed and, even if randomized, cannot be adapted to the ability of individual students nor provide individualized feedback. Similarly, standard MCQs ask students to identify particular features of a diagram, but cannot ask students to draw (or modify) one. The recent innovations in technology that we shall describe in this paper, however, may now allow instructors to bridge the gap between online and on site assessment and provide, if correctly explored, a path that may allow distant learning programmes to provide comparable learning outcomes to on site degrees.

\subsection{Advantages of adaptive questions and assignments}

Sometimes the answer to a particular question is not obvious to students, even if they may already have acquired the necessary knowledge to answer correctly the question. In this kind of situations, it may be greatly helpful to students to be given guidance and, in particular, be suggested alternative ways to answer the question and, perhaps, to approach the problem from a different angle. Let us consider the following example. Suppose that we are teaching an intermediate microeconomics module and attempting to expose students to a rigorous approach to (univariate) optimization. We can ask students to answer the following multiple choice question.

\section{Question 1}

Consider the function

$f(x)=2 \ln (x)+\frac{1}{2} x^{2}-3 x, \quad x>0$

By investigating the properties of this function, identify which of the statements is/are true.

a. $f(x)$ has a unique local maximum at $x=1$ and a unique local minimum at $x=2$.

b. $f(x)$ has a unique global maximum.

c. $f(x)$ has a global minimum at $x=0$.

d. $f(x)$ is strictly concave for $x \in(0, \sqrt{2})$ and strictly convex for $x>\sqrt{2}$.

Statements (a) and (d) are correct. In a standard type of multiple choice question, the student who does not identify the correct statements will get no mark (or negative marks) and, possibly, will be provided with the correct answer followed by feedback. This may be a little frustrating and disheartening to some students, and in particular those who have a general understanding of the basics of univariate function maximization. A student can acquire information reading the feedback, but the purpose of the question (allowing the student to identify important mathematical concepts and apply them to identify important features of a function) itself is somewhat moot. It would be preferable to ask the 
student to recollect the various concepts necessary to answer the question (i.e. concavity/convexity of a function, limit behaviour, first and second derivative of a function) and show him/her when and how to use these concepts to reach the right answer to the question. Ideally we would like to provide the student with a combination of encouragement (e.g. "You did not get it right. It's OK, let's approach the question step-by-step"), technical information (e.g. "recall that a function is concave if...") and additional questions (not necessarily multiple choice) to test his/her effective understanding. The student would learn this way how to identify important concepts and apply them correctly. Eventually, the student should be awarded (at least a portion of) the marks assigned to the correct answer. This is what any instructor would do in a one-to-one class or small group teaching, but cannot be replicated with standard online assignments. In section 3 we shall show how MapleTA allows instructors to construct adaptive questions that do precisely what we are suggesting and guide students step-by-step in online assignments.

\subsection{The importance of visual learning}

Visual material is very useful in supporting students' learning. It allows students to experience information and new concepts in a sensorial way and puts them in a position to be able to process more abstract reasoning. ${ }^{7}$ This is particularly true in economics. ${ }^{8}$ Visual learning is very important and effective and, when possible, should be used to complement and reinforce a more abstract approach to the subject. For example, in introductory modules, students sometimes may be over-exposed to mathematical expressions. In these situations diagrammatic analysis can be used to provide students with intuition and understanding. The same may be true also in those modules that cater for more heterogeneous cohorts, such as business and managerial economics classes. For example, students can be told that a monopolist will choose to supply a level of output such that marginal revenues equal marginal costs. They can also be asked to be able to calculate the monopoly quantity and price starting from a given demand and cost functions. If not exposed also to the diagrammatic analysis, there is, however, the risk that students will interpret the exercise in a very mechanical way and will miss the intuition behind the concepts of marginal curves and optimality. In this case, asking students to identify the profit maximizing level of

\footnotetext{
${ }^{7}$ This pedagogical approach has been adopted by the Montessori method of teaching mathematics to primary school children. Interestingly, algebraic and geometric concepts and procedures (for example how to calculate the cube of a binomial) can be easily and effectively taught to students using visual objects like the Montessori binomial cube (see http://www.infomontessori.com/videos.htm).

${ }^{8}$ See, for example, Vazquez and Chiang (2014). In addition, the pedagogical benefits of asking economics students to create their own media (photos and videos) containing economics insights have been recently identified by the literature. See, for example, Al-Bahrani et al. (2016) and Spielmann and Chaudhury (2016). The annual Royal Economic Society Undergraduate Video Competition (https://economicsnetwork.ac.uk/news/res_videocomp) is another example of the role that economics practitioners assign to the use of visual media to encourage students to learn and explore economics.
} 
quantity in a diagram would be appropriate. Indeed, it is often the case where students are asked to consider figures representing particular economic situations. However, this may not be enough. To really understand the connection with the mathematical expressions and then capture the economic intuition, students should also be asked to draw, shift and modify diagrams representing economic objects. ${ }^{9}$ For example, an elementary concept in microeconomics is that the marginal revenue function generated from a linear demand is linear too, with the same intercept and twice steeper than the demand function. Providing an exercise where students were given, for example, demand and cost functions and were asked to derive the marginal revenue and cost functions and draw the respective diagrams could be a very effective way to test important economic concepts.

Most virtual learning environments allow instructors to add figures and other types of media files (e.g. MP3 and videos) to the questions. Unfortunately, standard platforms at most allow instructors to upload files and create multiple choice questions referring to various aspects of the picture. In some cases, students can interact with the picture in clickable/hot-spot type of questions; in this type of questions students have to identify particular areas in the figures by clicking on them. This type of questions is very useful both in mathematics (students, for example, can be asked to identify a local/global maximum of a function represented in a diagram) and economics (students can be asked to identify the area of a diagram representing consumer surplus generated under monopoly). Clickable questions mostly focus on the ability of students to remember economic/mathematical concepts. It is often desirable, however, that students were also asked to learn how to draw a diagram and, especially in economics, the meaning of a graph in relation to other diagrams in a figure. Following the example above, it would be useful to ask students to draw basic diagrams (e.g. demand, marginal revenue, marginal costs) and ask to show how the diagrams are affected by specific changes in parameters (e.g. increase in consumers' willingness to pay or higher unit variable costs). In section 4 we shall show how MapleTA allows instructors to create both clickable and sketchthe-graph questions.

\subsection{The advantages of online assessment with MapleTA}

MapleTA is an online assessment platform based on the software for mathematical analysis Maple. MapleTA provides desirable features such as adaptive questions and clickable/sketch questions as described above, without most of the disadvantages found in standard virtual learning environments.

Compared to standard virtual learning environments, the key advantage resides in the fact that MapleTA is able to handle algebraic expressions. This

\footnotetext{
${ }^{9}$ Pezzino (2016) shows, for example, how the use of dynamic diagrams created with the software Mathematica can provide students with useful intuition regarding strategic competition among firms.
} 
feature is very important, particularly for those instructors interested in creating questions with some mathematical content; it is also important for those instructors of less quantitative modules, who still wish students to be familiar with and able to draw some functions (e.g. demand, cost, profits, etc.). Indeed, in economics modules it is often the case where instructors would like to write assignments with questions and answers that require mathematical expressions. Standard platforms, however, do not handle mathematics so well. In particular, the problem often resides with the recognition of algebraic expressions. For example, for most virtual learning environments the expression $a x+b$ is not equal to $b+a x$. This obviously makes writing questions and providing answers rather difficult and the learning experience of students (who will have to be told how to precisely insert their algebraic answers) rather unsatisfactory. In MapleTA, instead, $a x+b$ is equal to $b+a x$. Students just need to answer mathematical questions in any way they see fit and, as long as the answer is mathematically correct, ${ }^{10}$ they will get a full a score. In addition, instructors using MapleTA can use the powerful mathematical tools of Maple and access all its packages ${ }^{11}$. Specifically, MapleTA allows instructors to input an "algorithm", i.e. commands to create random variables, random matrices, functions and plots. Figure 1 shows how to create an algorithm to produce a random square matrix of (randomly selected) degree $2 \leq n \leq 4$.

\section{FIGURE 1 HERE}

The line $e^{12}$

$$
\$ n=i n t(\operatorname{rand}(2,4))
$$

assigns the name $n$ to a random integer between 2 and 4 .

The line

\$matrix=maple("randomize():LinearAlgebra[RandomMatrix](\$n,\$n,generator $=$ rand(-

$$
\text { 9..10))") }
$$

calls the Maple package LinearAlgebra and generates a random matrix with $n$ columns and $n$ rows and elements between -9 and 10 .

Finally, line

$$
\text { \$m=maple("printf(MathML:-ExportPresentation(\$matrix))") }
$$

\footnotetext{
${ }^{10}$ MapleTa essentially takes the difference between the student's response and the expression that the instructor inserted. If the difference of the two expressions is equal to zero, then the answer is marked as correct.

${ }^{11}$ Caveat: some of the commands of MapleTa sometimes may differ from Maple commands. For example, suppose that you want to call the LinearAlgebra package and create a $2 \times 2$ random matrix. In Maple you would have to insert LinearAlgebra[RandomMatrix](2), while in MapleTa the command would be maple("randomize():LinearAlgebra[RandomMatrix](2)").

${ }^{12}$ To create a new object in MapleTa the name has to follow the dollar $\$$ symbol.
} 
displays the random matrix. ${ }^{13}$ Figure 1 also shows how MapleTA provides an example of the output of the algorithm in this particular case.

Once the mathematical object has been created, the instructor can use it in a question. For example, the student may be asked to provide the determinant of square matrix $\mathrm{A}=\$ \mathrm{~m}$. In the response area (i.e. the area in MapleTA where instructors are asked to insert the right answer to the question) the instructor can use the following line to ask MapleTA to use the Maple package LinearAlgebra and the command Determinant ${ }^{14}$

\section{LinearAlgebra[Determinant](\$matrix)}

The advantage of algorithmic questions is that the mathematical objects created by the algorithm can change every time the student accesses the question (if allowed multiple attempts) and each student will face slightly different mathematical expressions. In addition, questions can be cloned, i.e. replicated. For example, if an instructor wanted students to practice on finding the roots of polynomials, she could create a question with an algorithm that randomizes the coefficients of the equation, ${ }^{15}$ and then clone it. This way there would be two different questions with different equations for students to solve. ${ }^{16}$

In MapleTA instructors can upload any figure (e.g. diagrams, tables) and create clickable questions where students are asked to identify and click on the correct area(s) of the picture. In section 4 we shall provide examples of clickable questions on economics topics.

In addition to clickable questions, MapleTA provides instructors and students also with a useful toolbox for sketching the diagram of mathematical functions. In section 4 we describe how to use this toolbox to create meaningful questions requiring the students to sketch, translate or modify (set of) diagrams. We shall also show how to use algorithms to create plots that can be used to provide feedback and hints to students.

A final remark. A very important advantage of MapleTA is provided by the MapleTA Connector, i.e. the application that allows instructors to create,

\footnotetext{
${ }^{13}$ Notice that we have created two different objects. \$matrix is the mathematical object that MapleTA uses in the algorithm. This object does not look like a standard matrix. To allow the user to see the matrix in the standard format (i.e. a collection of elements organised in rows and columns enclosed in brackets) we need to create another object, $\$ m$, to display the matrix to the user.

${ }^{14}$ Note the difference between $\$ \mathrm{~m}$ and $\$$ matrix.

${ }^{15}$ The algorithm to create a quadratic equation (and find related roots) would be as follows. $\$ a=$ range $(-10,10)$;

$\$ \mathrm{~b}=$ range $(-10,10)$

$\$ c=$ range $(-10,10)$;

$\operatorname{solve}\left(\$ \mathrm{a}^{*}\left(\mathrm{x}^{\wedge} 2\right)+\left(\$ \mathrm{~b}^{*} \mathrm{x}\right)+(\$ \mathrm{c})=0, \mathrm{x}\right)$

${ }^{16}$ Caveat: while cloning is a very useful feature of MapleTA, the excessive use of this feature may make the assignments rather repetitive and unengaging. We shall discuss our experience in $\mathrm{UG}$ modules regarding this in section 5. It is good practice to structure every assignment with a well-balanced set of questions. It is also essential to carefully explain to students what the intended objective of each assignment is.
} 
edit and release MapleTA assignments directly in a virtual learning environment. This is a major advantage. Students will not need to be provided an additional set of access details to use the software. Moreover, the assignments will be completely integrated in a learning environment that is already familiar to students. Similarly, the grades that students obtain in MapleTA assignments are automatically imported in the gradecentres of the learning environments. Currently, MapleTA can be managed by instructors and accessed by students in Blackboard, Canvas, Moodle, Brightspace and Sakai.

The software clearly provides important pedagogical benefits. The possibility to create and clone mathematically rigorous questions provides useful practice to students and, following Bloom's taxonomy, helps them remembering and understanding important economic and mathematical concepts. Similarly, questions based on visual material require students to interact with the questions and, consequently, acquire a deeper understanding that allows them to evaluate and analyze complex problems.

\section{Adaptive questions in MapleTA}

In MapleTA a question has adaptive features if students are prompted with an additional, and related, subquestion in case they got the main question wrong. This way instructors can step by step guide and support students in finding alternative ways to answer the original question. If carefully conceived, essentially every question in MapleTA can be adaptive and contain a mix of various types of questions. In what follows, for expositional clarity, we shall describe an adaptive question based on question 1 in section 2.1. We shall also show how visual questions can be constructed in an adaptive way. However, any other combination could also be considered; for example, an initial MCQ, followed by a clickable question, followed by a numeric question, etc.

Figure 2 provides the MCQ version of question 1 in section 2.1. The question has been set so that, after one incorrect attempt (the instructor can decide the number of attempts allowed before MapleTA triggers the adaptive content), the system will provide additional information, feedback and questions.

\section{FIGURE 2 HERE}

Figure 3 shows what happens if the question is not answered correctly. The answer is marked as incorrect, but an additional portion of the window is now visible to the student. The instructor is free to use the adaptive content as (s)he sees fit. In this case we decided to give, after some encouragement and explanation, a few hints regarding the limit behaviour of the function (discarding alternatives b and c) and asking students to find the first and second derivative of the function to identify stationary points and concavity/convexity properties.

FIGURE 3 HERE 
Figure 4 shows how the MapleTA question editor looks like when questions have adaptive content. The top half of the window creates the initial question. Clicking on the button circled in red in figure 4 creates a divisor in the question editor window and everything below the divisor will be treated by MapleTA as adaptive content and will be released if the student gets the initial question wrong.

\section{FIGURE 4 HERE}

When clicking on the adaptive question button, this opens a window that allows the instructor to choose the options regarding the adaptive part of the question, see figure 5. The instructor can decide how many attempts to allow before triggering the adaptive content and the marks assigned to each subquestion.

\section{FIGURE 5 HERE}

Of course, diagrammatic questions can be made adaptive too. ${ }^{17}$ For example, suppose a student is asked to sketch the diagram of demand function $P=10-Q$, the corresponding marginal revenue function and the marginal cost function related to cost $C(Q)=2+2.5 Q$. The question requires the student to know (i) the concept of linear functions, (ii) the features of a marginal revenue function related to a linear inverse demand function, (iii) the concept of marginal cost function and how to derive it from a total cost function. A mistake or imprecision on any of the aspects above will affect the performance of the student that, without the opportunity provided by adaptive questions, would get the full question marked as incorrect. Indeed, figure 6 shows the case where the initial question is incorrectly answered.

\section{FIGURE 6 HERE}

This triggers the adaptive content shown in figures 7 and 8 . In figure 7 the student is given some information and asked to draw the demand function. In this case the student is given one attempt before the correct answer is provided and additional adaptive content (shown in figure 8) is released. Notice that in figure 8 the demand function is already shown on the plane. We chose to release the correct answer to the previous section to allow the student to focus on the new task, i.e. drawing the marginal revenue function.

FIGURE 7 HERE

FIGURE 8 HERE

Figure 9 shows the last portion of the adaptive content released to the student.

\section{FIGURE 9 HERE}

\footnotetext{
${ }^{17}$ We shall describe in section 4 how to create sketch-the-graph questions.
} 
In this example the original question was allocated a mark of 1 . Thanks to the adaptive content, the student does not have to be given a mark of zero (or a negative one) for not answering correctly the original question. Accessing the options in the window shown in figure 5, the instructor can decide how to allocate marks among the adaptive sections of the question. For example, suppose that each adaptive section is allocated 0.3 marks. Then, if the student answers the initial question correctly, (s)he will get 1 full mark. Otherwise, if (s)he answers the adaptive sections correctly will get at most 0.9 . Of course, if no adaptive question is answered correctly, the student will end up with no marks. The advantage here is that adaptive questions allow the instructor not to over-penalize the student who struggled initially identifying the right concepts and knowledge to use to answer the question. This should encourage students in their learning.

Notice that MapleTA assignments can be made adaptive too. Questions are organized according to different degrees of difficulty. The particular questions that students will encounter in the test will depend on their responses in previous questions. Specifically, if a student answers a question correctly, the following question becomes more difficult. If the student does less well, the questions selected become less difficult. The use of computerized adaptive testing (CAT) has become a widespread practice in education (Weiss and Betz (1973), Weiss and Kingsbury (1984)). It only requires a large pool of questions and an algorithm that then selects individual questions for students. The advantages of adaptive assessment cannot be overrated. Adaptive tests have in particular the advantage to make a test sufficiently challenging for all students without providing a frustrating and discouraging experience to those students who are struggling with the material (Kingsbury and Houser (1998), Thissen and Mislevy (2000)).

\section{Visual learning in MapleTA. Clickable and sketch- the-graph questions.}

In this section we show how to create questions that ask students to draw and interact with diagrams and other visual material. Figure 10 provides an example of a clickable question in MapleTA. The example shows a pay-off matrix of a simple simultaneous move game where the student is asked to click on the best response of Player 2 if Player 1 chose action $M$. Of course, the same question could have been provided in the form of a traditional MCQ, where the student had to identify the right answer out of, say, four alternatives. The clickable question, however, requires the student to directly interact with the whole matrix and to consider the whole set of payoffs, rather than a subset of alternatives preselected by the instructor.

FIGURE 10 HERE 
Consider another example. The question in figure 11 asks the student to identify the area of the graph representing consumer surplus when the market is served by a profit maximizing monopolist. Using the clickable image format, the instructor does not have to find rather awkward ways to identify the different parts of the diagrams (i.e. "triangle ABC", "rectangle DEF", etc.). The student is, instead, asked to interact directly and immediately with the graph.

\section{FIGURE 11 HERE}

Clickable images are an excellent way to make the student interact with a diagram. In economics, however, it is often important to ensure that the student is also able to reproduce, translate or modify a graph. Going back to the previous example, it is indeed often the case where students are able to identify the area of a graph representing consumer surplus. Fewer students, however, are able to identify the consumer surplus area, being given only the functional forms of demand and cost functions.

In order to draw a graph, students will need to use the graphical toolkit located on the top of the plane where the diagram should be created. Using the toolkit is very simple and intuitive. For example, to draw a linear function students only require to click on any two points on the plane and the software will produce a continuous line (that can be snipped if necessary). The line can, of course, be then translated simply dragging and dropping the two points initially used to create the diagram. A similar procedure should be used for more complex diagrams (that may require students to identify more than two points on the plane). The question in figure 12 asks students to derive and sketch the marginal revenue and marginal cost functions of given linear demand and cost functions.

Figure 12 here.

Given the graphical toolkit in MapleTA, students can also be asked to consider the effects on the diagrams of exogenous changes in parameters. For example, given the demand and cost functions considered in figure 6 , the student can be asked to sketch the graphs of a new demand function (say $P(Q)=15-Q$ ) and the marginal cost related to a new cost function (say $C(Q)=7+10 Q$ ). Comparing the diagrams of the new and original functions, the student can understand practically the diagrammatic effect of a change in the willingness to pay of consumers (i.e. the vertical intercept of the demand function) and the marginal cost of production.

When creating a sketch-the-graph question, the instructor, after inserting the text of the question (e.g. "Draw the graph of the following function"), can access the same graphical toolkit used by students and draw the required diagram (see figure 13). In some situations, the instructor may want students to 
draw diagrams on a plane that already shows other diagrams. This is particularly useful for example when asking students to consider the effects of changes in parameter values when performing comparative statics analysis. MapleTA allows the instructor to insert the mathematical expressions of functions that will be shown on the plane when students will attempt to answer the question (see figures 14 and 15).

Figure 14 here.

Figure 15 here.

Of course, clickable image and sketch-the-graph features can appear in the same question. In other words, MapleTA allows instructors to create questions in which students are asked to sketch a diagram and, then, click on specific areas of the graph. This type of questions provides a very good application of the adaptive features of MapleTA that we have discussed in section 3.

Finally, notice that MapleTA allows instructors to provide diagrams based on an algorithm that can be inserted both in the main text of a question and in the feedback area. Figure 16 shows a question on an asymmetric Cournot duopoly. Specifically, students are given a (linear) demand and two cost functions, and are asked to derive the best response functions of the duopolists. The coefficients of the demand and cost functions are randomly created by the following algorithm:

$$
\begin{aligned}
& \$ a=\operatorname{range}(1,5,1) ; \\
& \$ b=\operatorname{range}(1,5,1) ; \\
& \$ c=\operatorname{range}(1,5,1) ; \\
& \text { condition:gt }(\$ a, \$ b) ; \\
& \text { condition:gt }(\$ a, \$ c) ;
\end{aligned}
$$

\section{FIGURE 16 HERE}

The code creates three variables that are integers between 1 and 5 and ensures that variable $a$ is greater than variables $b$ and $c$. The functions created in the MapleTA question editor are $p=\$ a-q 1-q 2, C(q 1)=\$ b q 1$ and $C(q 2)=\$ c q 2$. In this kind of exercise it is often the case in which students learn a recipe to solve the problem (i.e. identify the profit functions, take the first derivative of the profit functions to find first order conditions and solve with respect to the appropriate quantity to find the best response function). The question in figure 16 does precisely this. In addition, however, it provides additional support and intuition displaying (see figure 17) the diagram of the best response functions.

\section{FIGURE 17 HERE}


Notice that, thanks to the MapleTA algorithm, ${ }^{18}$ the diagrams are created according to the particular values that variables $a, b$ and $c$ have been assigned in the question (in the example in figures 16 and 17 we have that $a=4, b=3=c$ ). Since the question is built around an algorithm, different students will access different questions and will be shown different diagrams. The advantage is that, instead of being exposed to standardized question and diagrams, students are asked to interact with always slightly different mathematical expressions that produce different diagrams. It follows that students will have to understand the meaning of the diagram and its key features (e.g. in the case of linear functions, intercepts and slopes). In addition, the diagrams can be released to students as hint (i.e. information available to students while attempting a question) or as feedback (released after the question has been attempted) to students.

\section{Qualitative evaluation of the use of MapleTA in UG Economics modules}

The objective of this paper is not promoting specifically the use of MapleTA, but to highlight the significance and advantages of online tests based on visual and adaptive questions, in particular if supported by an effective system able to handle mathematical expressions well. However now, to reinforce the points made in previous sections, it may be nonetheless useful to provide a qualitative evaluation of MapleTA and describe our experience in UG Economics modules at the University of Manchester.

At the beginning of the academic year 2015/2016 the University of Manchester piloted the use of MapleTA. After joining the pilot, we introduced MapleTA in Advanced Mathematics (year 1 undergraduate module, compulsory for Economics students with A-Levels Maths). ${ }^{19}$ In academic year 2016/17 we, then, adopted MapleTA in Business Economics II (year 3 undergraduate module, compulsory for Business Studies students).

The use of MapleTa, not surprisingly, comes with costs and benefits. Leaving aside the financial costs incurred by the institution to purchase the MapleTA license, it is important to first consider the costs for the module convenor. There are definitely fixed costs that need to be incurred by an instructor to learn how to use the software. Since we never previously used the mathematical software Maple, we had to learn about Maple in general (e.g. commands, various mathematical packages, etc.) and MapleTA specifically (e.g. how to create a class in Blackboard, how to create/clone questions, types of assignments, etc.). These

\footnotetext{
${ }^{18}$ To create the diagrams, the following code need to be added to the algorithm:

$\$$ br1 = plotmaple("plot $\left((\$ a-\$ b-q 2)^{*}(1 / 2), \mathrm{q} 2=0 . .1\right)$, plotoptions='height=350, width=350'" $)$; $\$$ br2 $=$ plotmaple("plot $\left(\$ a-\$ \mathrm{c}-\left(2^{*} \mathrm{q} 2\right), \mathrm{q} 2=0 . .1\right)$, plotoptions='height=350, width=350'");

The instructor, then, can recall the diagrams of the best response functions using objects $\$ b r 1$ and $\$ b r 2$ in the main text and, if desired, in the feedback area of the question.

${ }^{19}$ The only other module that piloted MapleTA in academic year 2015/16 was State-Space and Multivariable Control (MSc module provided by the School of Electrical and Electronic Engineering).
} 
costs can be incurred relatively easily; the interface is very intuitive, easy to navigate and there is plenty of support available online, including a MapleTA community with useful tutorials. ${ }^{20}$ We also had the advantage to have in-house support and guidance from our eLearning technologist; she was also in contact with support from MapleSoft. Creating standard MCQs in MapleTA requires essentially the same steps as in any virtual learning environment. Learning how to create algorithmic questions (with random variables, diagrams and the use of mathematical packages such as LinearAlgebra) will definitely require more effort. Compared to the latest release of MapleTA (on which all examples provided in this papers have been created), the 2015/2016 release presented a few (minor) bugs related to the equation editor and a major issue concerning the clickable image questions. ${ }^{21}$ These problems have been fixed in the current MapleTA release. Students incur almost zero costs to use MapleTA since the content is fully integrated in the virtual learning environment with which they are already familiar. Our students (who had not previously used Maple software) had not problem inserting their answers using the equation editor or creating diagrams using the graphical toolkit.

The key benefits of adopting a system like MapleTA have been described in previous sections (see in particular section 2.3). We have used MapleTA assignments as formative assessment, in the form of pre-maths tests at the beginning of a module, weekly assignments, past and mock exam papers. We have exploited the different features of MapleTA tests in order to meet specific needs of students. In what follows we describe our experience of introducing MapleTA in year 1 Advanced Mathematics and year 3 Business Economics modules.

Advanced Mathematics. The course serves various programmes, such as BA Economic and Social Studies, BSc Economics, International Business Finance and Economics, Politics, Philosophy and Economics (PPE). In 2015/16 about 600 students were enrolled in the module and all held A-level mathematics or equivalent qualification.

We introduced MapleTA to meet the specific needs of some students. Indeed, even if the virtual learning environment and the textbook both provided a large set of exercises, some students expressed the need for additional practice. To support these students, we decided to produce a number of algorithmic questions (algebraic questions with random variables automatically marked by MapleTA) and clone them. This way students could essentially access an unlimited number of tests, all showing different numerical questions. Other students were very confident in their calculations, but struggled in understanding diagrammatic analysis of functions; for example, some were very comfortable and proficient in calculating the derivative of a function, but they would struggle identifying

\footnotetext{
${ }^{20}$ See https://mapletacommunity.com/. The site provides also useful videos released by MapleSoft.

${ }^{21}$ The technical problem related to the clickable image questions was attributable to the fact that the release was built on Java. This implied that students using Apple computers or accessing the resources on browsers that did not support Java (i.e. Chrome) were not able to load the question.
} 
the difference between a global and a local maximum. For these students we produced questions that asked to sketch the graph of particular functions or to click on areas of a diagram to identify particular sections (e.g. the global/local maximum, inflection point, the long run equilibrium of a difference equation, etc.). There was also a number of students who found the standard exercises provided in the virtual learning environment too difficult. For these students we decided to produce adaptive questions to gradually introduce them to particularly complex mathematical concepts and provide them with step-by-step instructions available while answering the questions.

The Advanced Mathematics students were asked to submit MapleTA assignments (formative only) that included about 20 clickable image questions and 35 practice questions based on cloned algorithms.

The final exam of the module was 100\% MCQ based. Because of this, the adoption of online assessment was very welcomed by the class. Students were also given a mock exam (in structure identical to the final exam). To provide students with immediate feedback and support with the mock exam, I decided to turn the mock into a MapleTA assignment, allowing students to access the test multiple times.

In semester 2 of academic year 2015/2016 we released a survey among the Advanced Mathematics students to obtain feedback on their experience with MapleTA.

On the whole students reported a positive experience with the software. Examples of the open comments are:

- The assignment is quite simple and repetitive (this is how I learn mathematics). Make a mistake and find the same type of question with different numbers.

- I think the MapleTA is a great one.

Of course, most of them found the technical issues related to the clickable image questions rather frustrating:

- Most questions don't load in Chrome or Explorer meaning I could only answer around half the questions.

- The test become impossible to take because pictures would not appear on screen.

Some did not also appreciate the fact that a number of questions in the assignment where rather similar due to the cloning:

- The same questions were repeated several times and most elements would not display.

We now believe that it would have been a better practice to produce various tests, each mostly containing a particular type of question and aiming to serve a 
particular student need (e.g. calculation practice, diagrammatic understanding, adaptive and interactive learning, etc.). If properly informed, students would have been able to choose which test to take in order to satisfy their particular learning need. Instead, asking students to take undifferentiated tests created some frustration among those who could not understand why they were asked to solve (repeatedly) particular types of questions. At the end of the semester we discussed these comments with the class. We acknowledged that the tests may have been too repetitive and shared what we learned with them.

The survey also asked students the following question: "Would you recommend MapleTA for future students?". Students' response was: $53 \%$ agree, $20 \%$ disagree, $27 \%$ unanswered. In addition, $59 \%$ of students preferred MapleTA compared to other assessment methods (e.g. Blackboard online quizzes). Given that the students compared their experience with the use of a large (and bugfree) set of Blackboard multiple choice quizzes available for them, the fact that the majority of the class preferred the old release of MapleTA to Blackboard quizzes is noteworthy. ${ }^{22}$

Compared to previous years, the only innovation introduced in the module in 2015/16 was the use of MapleTA assignments. Textbook, syllabus, lecturer and assessment structure had remained unchanged. The structure of the final exam (thirty multiple choice questions with five possible answers each and no negative marking), remained also unchanged. Table 1 shows that the final grade distribution was significantly favorable to the $2015 / 16$ class.

\section{TABLE 1 HERE}

Of course, we do not believe that the introduction of online assessments based on MapleTA could have been the only factor that helped improving so substantially the performance of the class. Another factor that may have contributed to the improved performance may have been the fact that, because an administrative problem, the 2015/16 class had the advantage to take the exam a week after the end of the official examination period. This provided the class with additional revision time for the exam. Nonetheless, even allowing for the

\footnotetext{
${ }^{22}$ The same questions were also asked to the MSc Engineering students. This was the first type of online assessment for them. The impressions of the postgraduate engineering students were on the whole very positive. They clearly appreciated the advantages of online assessment (in particular the immediate feedback) and the treatment of mathematical objects such as matrices. In contrast to the UG students, they appreciated also the repetition and adaptability in the assignments.

Students commented:

- Compared with questions on Blackboard, Maple is more professional for editing matrices.

- As an online test, the requirements for the assignment, such as deadline and passing scores, are posted clearly so it is impossible for us to forget or miss.

- A more important reason for me to think Maple is better than paper quiz is that Maple gives feedback immediately after submission. This allows us to know where our problems are so that we can repeat the test and improve our marks.
} 
effect of the increased revision time, the improvement in the grade distribution in the year MapleTA was introduced remains remarkable. From 2016/17 the module has been taught by a different convenor and, therefore, considering comparisons in terms of students' performance after 2016 may be misleading.

Business Economics II. Business Economics II is a compulsory module for those students on the Business Studies pathway of the BA Economic and Social Studies degree. The module is also open to every student, regardless of programme of study, who meets the pre-requisites (year 2 Business/Managerial Economics or Microeconomics). This implies that among the 250 students usually enrolled in the module, there are students who have a good economic/mathematical background, but also students who are familiar only with basic economic concepts and possess minimal mathematical skills. The student cohort tends to be, therefore, very heterogeneous in terms of academic interests and mathematical skills. The module exposes students to a series of oligopoly models used to study particular sectors (e.g. banking, health care) and forms of competition (e.g. mixed oligopoly, corporate social responsibility) and it is critical that all students acquire as soon as possible the essential tools to study oligopoly models and appreciate the economic intuition behind them. In 2016/17 we introduced a compulsory MapleTA pre-maths test for all students to take at the beginning of the module. Students who did not do well were then asked to seek further support and were provided with extra material, including additional MapleTA maths tests, similar to those we used in Advanced Maths. A common issue that we have encountered in the past teaching this module is that often the mathematically confident students lack a deep understanding of the necessary economic and graphical intuition behind a model. Because of this, we released MapleTA tests based on clickable and sketch-the-graph questions where students were asked to reproduce and understand the use of best response functions and comparative statics analysis in oligopoly games. Thanks to the algorithmic power of MapleTA, we were able to produce (demand, cost, profit) functions with randomized parameters and ask students to solve analytically and graphically a large number of duopoly games.

We can offer only anecdotal evidence regarding the students' opinion of the adoption of MapleTA. In general they found particularly useful the use of visual questions and the possibility to solve exercises that asked them to find the equilibrium of duopoly games. Students could clearly identify the benefit of this formative assessment toward their preparation for the midterm test released in November. The midterm required students to solve analytically and graphically a duopoly game and discuss a simple exercise of comparative statics analysis. The performance of the class on average significantly improved compared to previous years (where the syllabus, lecturer and content of the midterm where essentially unchanged).

Table 2 here. 
In academic year 2016/2017 no technical issue with MapleTA was reported and other economics modules adopted assignments based on the new MapleTA release. Specifically, MapleTA has been adopted in Economics of Environmental Management (year 2 UG module) both as formative and summative assessment; Business Economics I (year 2 UG module) as formative assessment only. Colleagues (none of which had previously used Maple software) found the MapleTA interface friendly and encountered no particular problem in creating algorithmic or graphical questions. The fact that we had pioneered the system and could provide some assistance, clearly, facilitated the adoption of the software in the department. Colleagues confirm that they shall continue using the software in 2017/18. In addition, MapleTA assignments have been released in a Blackboard Community ("Mathematics Resources for Social Scientists") open to all students registered to economics modules (regardless of the year of study or the particular School to which they belong).

\section{Conclusions}

Recent technological innovations have significantly improved important features of online assessment, like increased adaptability and management of visual material. In this paper we have shown examples of how such improvements can benefit students and instructors. The advantages are particularly important in distant learning programmes and in those on site large modules where personal interaction is not always feasible. We made use of the online assessment platform MapleTA to provide examples and applications. We also provided a few caveats. It is important, in particular, that the instructor who decides to introduce this innovation carefully assesses the pedagogical needs of the class and the costs/benefits associated to introducing new assessment practices. We would also like to offer a final, important, caveat. Some students may find confusing to access different platforms simultaneously. Currently, MapleTA is fully integrated to Blackboard and other popular virtual learning environments. This means that students (and instructors) do not require additional log in sessions to access the online assignment (or edit the material). In addition, every score obtained after submitting a MapleTA assignment is automatically recorded in the learning environment gradecentre. The possibility of offering students online assessment built on specialized platforms such as MapleTA (or any similar type of software) should be carefully considered only if the standard virtual learning environment used in their institution supports the use of the software.

\section{References}

Al-Bahrani, A., Holder, K., Moryl, R.L., Murphy, P.R. and Patel, D., 2016, "Putting yourself in the picture with an 'ECONSelfie': Usingstudent-generated photos to enhance introductory economics courses", International Review of Economics Education 22, 16-22. 
Bishop, J. L., \& Verleger, M. A., (2013), "The flipped classroom: A survey of the research" in ASEE National Conference Proceedings, Atlanta, GA. https://www.asee.org/public/conferences/20/papers/6219/view.

Chalmers, D, and . McAusland, W. D. M , 2002, "Computer-assisted Assessment", in The Handbook for Economics Lecturers (chapter edited by Houston, J. and Whigham, D.), The Economics Network, pp 1-20

Chan, D., 2006, The Role of ICT in a Constructivist Approach To the Teaching of Thinking Skills, http://static1.1.sqspcdn.com/static/f/1751776/20693267/1350729059353/ICTin-Constructivist-Teaching-of-Thinking-Skills.pdf?token=KCFLTJU4InxVka1Ses\%2FZr6yv9jI\%3D

Hannay, M., Newvine, T., 2006. Perceptions of distance learning: a comparison of online and traditional learning. Journal of Online Learning and Teaching 2 (1), http://jolt.merlot.org/documents/MS05011.pdf

Hoover, W.A., 1996, The Practice Implications of Constructivism, SEDL Letter Volume IX(3), http://www.sedl.org/pubs/sedletter/v09n03/practice.html

Howsen, R., Lile, S., 2008. "A comparison of course delivery methods: an exercise in experimental economics". Journal of Economics and Finance Education 7 (1) 21-28.

Kingsbury, G. G., Freeman E.H., and Nesterak, M., 2014, Using Assessments Thoughtfully, Educational Leadership, 71 (6), http://www.ascd.org/publications/educationalleadership/mar14/vol71/num06/The-Potential-of-Adaptive-Assessment.aspx

Kingsbury, G. G., \& Houser, R. L. (1998). Developing computerized adaptive tests for school children. In F. Drasgow \& J. B. Olson-Buchanan (Eds.), Innovations in computerized assessment (pp. 93-116). Mahwah, NJ: Erlbaum.

Lage, M. J., Platt, G. J., \& Treglia, M., (2000), "Inverting the classroom: A gateway to creating an inclusive learning environment", The Journal of Economic Education, 31(1), 30-43.

Means, B., Toyama, Y., Murphy, R. , Bakia, M. and Jones, K., 2010, "Evaluation of Evidence-Based Practices in Online Learning: A Meta-Analysis and Review of Online Learning Studies", U.S. Department of Education Office of Planning, Evaluation, and Policy Development. http://www2.ed.gov/rschstat/eval/tech/evidencebased-practices/finalreport.pdf

Olczak, M., 2014, "Evaluating the impact of a web-based resource on student learning", International Review of Economics Education 16, 156-169

Pezzino, M., 2016, "Understanding strategic competition using numerical simulations and dynamic diagrams in Mathematica", International Review of Economics Education, 22, 34-47. 
Pezzino, M., 2017, "The Use of Media and Technology in the Classroom" in The Handbook for Economics Lecturers, Elliott, C. (ed.). The Economics Network.

Raymond, F., Raymond A. and McCrickard, M., 2008, "Stuck Behind the Math: Just How Helpful Can One Expect Technology to be in the Economics Classroom?", International Review of Economics Education, 7, 62-102.

Roach, T., (2014), "Student perceptions toward flipped learning: New methods to increase interaction and active learning in economics", International Review of Economics Education, 17, 74-84.

Spielmann, C. and Chaudhury, P., 2016, "Let's make a movie! - Introducing economics with a multimedia research project", Journal of Economics Teaching, $1,16-41$.

Stephenson, J. and Cortinhas, C., 2013, "Creative uses of in-class technology", in The Handbook for Economics Lecturers (chapter edited by Latreille, P.), The Economics Network.

Thissen, D., \& Mislevy, R. J. (2000). Testing algorithms. In H. Wainer (Ed.), Computerized adaptive testing: A primer (pp. 101-134). Mahwah, NJ: Erlbaum.

Vazquez, J.J. and Chiang, E.P., 2014, "A picture is worth a thousand words (at least): The effective use of visuals in the economics classroom", International Review of Economics Education 17, 109-119.

Watts, M. and Schaur, G., (2011), "Teaching and Assessment Methods in Undergraduate Economics: A Fourth National Quinquennial Survey", The Journal of Economic Education, Vol. 42, Issue 3, pp. 294-309.

Weiss, D. J., \& Betz, N. E. (1973). Ability measurement: Conventional or adaptive? (Research Report 73-1). Minneapolis: University of Minnesota, Department of Psychology.

Weiss, D. J., \& Kingsbury, G. G. (1984). Applications of computerized adaptive testing to educational problems. Journal of Educational Measurement, $31,361-375$.

Yamarik, S., (2007), "Does cooperative learning improve student learning outcomes?", The Journal of Economic Education, 38(3), 259-277. 


\begin{tabular}{|llll|}
\hline Class & $\mathbf{2 0 1 3 / 1 4}$ & $\mathbf{2 0 1 4 / 1 5}$ & $\mathbf{2 0 1 5 / 1 6}$ \\
$\mathbf{0 - 2 9}$ & $2.77 \%$ & $2.76 \%$ & $0.61 \%$ \\
$\mathbf{3 0 - 3 9}$ & $3.62 \%$ & $4.60 \%$ & $0.61 \%$ \\
$\mathbf{4 0 - 4 9}$ & $11.73 \%$ & $14.94 \%$ & $2.44 \%$ \\
$\mathbf{5 0 - 5 9}$ & $21.75 \%$ & $22.07 \%$ & $6.71 \%$ \\
$\mathbf{6 0 - 6 9}$ & $23.24 \%$ & $23.45 \%$ & $14.33 \%$ \\
$\mathbf{7 0 - 1 0 0}$ & $36.67 \%$ & $32.18 \%$ & $75.30 \%$ \\
\hline
\end{tabular}

Table 1: grade distribution comparisons in the final assessment of Advanced Mathematics.

\begin{tabular}{|llll|}
\hline Class & $\mathbf{2 0 1 3 / 1 4}$ & $\mathbf{2 0 1 4 / 1 5}$ & $\mathbf{2 0 1 5 / 1 6}$ \\
$\mathbf{0 - 2 9}$ & $4 \%$ & $6 \%$ & $2 \%$ \\
$\mathbf{3 0 - 3 9}$ & $1 \%$ & $1 \%$ & $2 \%$ \\
$\mathbf{4 0 - 4 9}$ & $12 \%$ & $5 \%$ & $9 \%$ \\
$\mathbf{5 0 - 5 9}$ & $27 \%$ & $17 \%$ & $15 \%$ \\
$\mathbf{6 0 - 6 9}$ & $27 \%$ & $38 \%$ & $27 \%$ \\
$\mathbf{7 0 - 1 0 0}$ & $29 \%$ & $32 \%$ & $45 \%$ \\
\hline
\end{tabular}

Table 2: grade distribution comparisons in the midterm assessment of Business Economics II. 


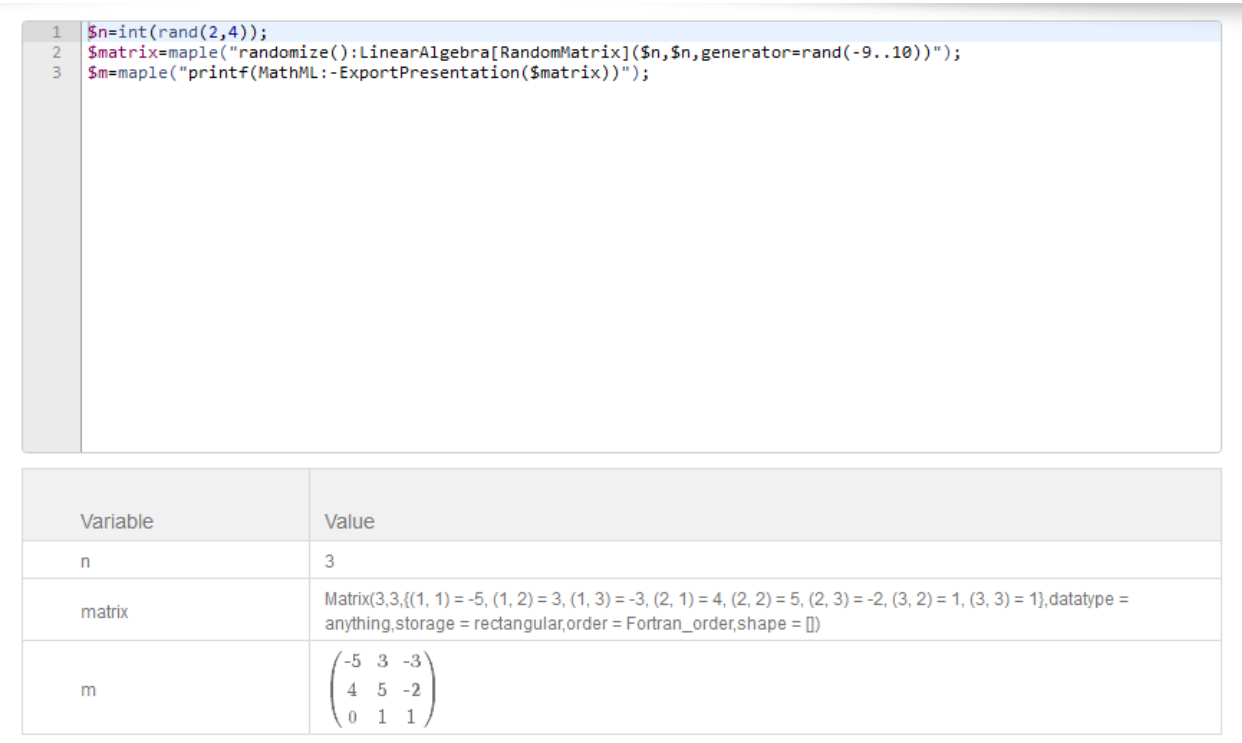

Figure 1: example of MapleTA algorithm

Consider the function

$$
f(x)=2 \ln (x)+\frac{1}{2} x^{2}-3 x, \quad x>0 .
$$

By investigating the properties of this function, identify which of the statements is/are true.

$$
\begin{aligned}
& \square f(x) \text { has a unique local maximum at } x=1 \text { and a unique local minimum at } x=2 \text {. } \\
& \square f(x) \text { has a unique global maximum. } \\
& \square f(x) \text { has a global minimum at } x=0 . \\
& \square f(x) \text { is strictly concave for } x \in(0, \sqrt{2}) \text { and strictly convex for } x>\sqrt{2} \text {. }
\end{aligned}
$$

\section{Attempt 1 of $1 \quad$ Verify}

Figure 2: MapleTa multiple choice question with adaptive content. The question specifies how many attempts are available before the adaptive content is released. 
Page 24 of 37 


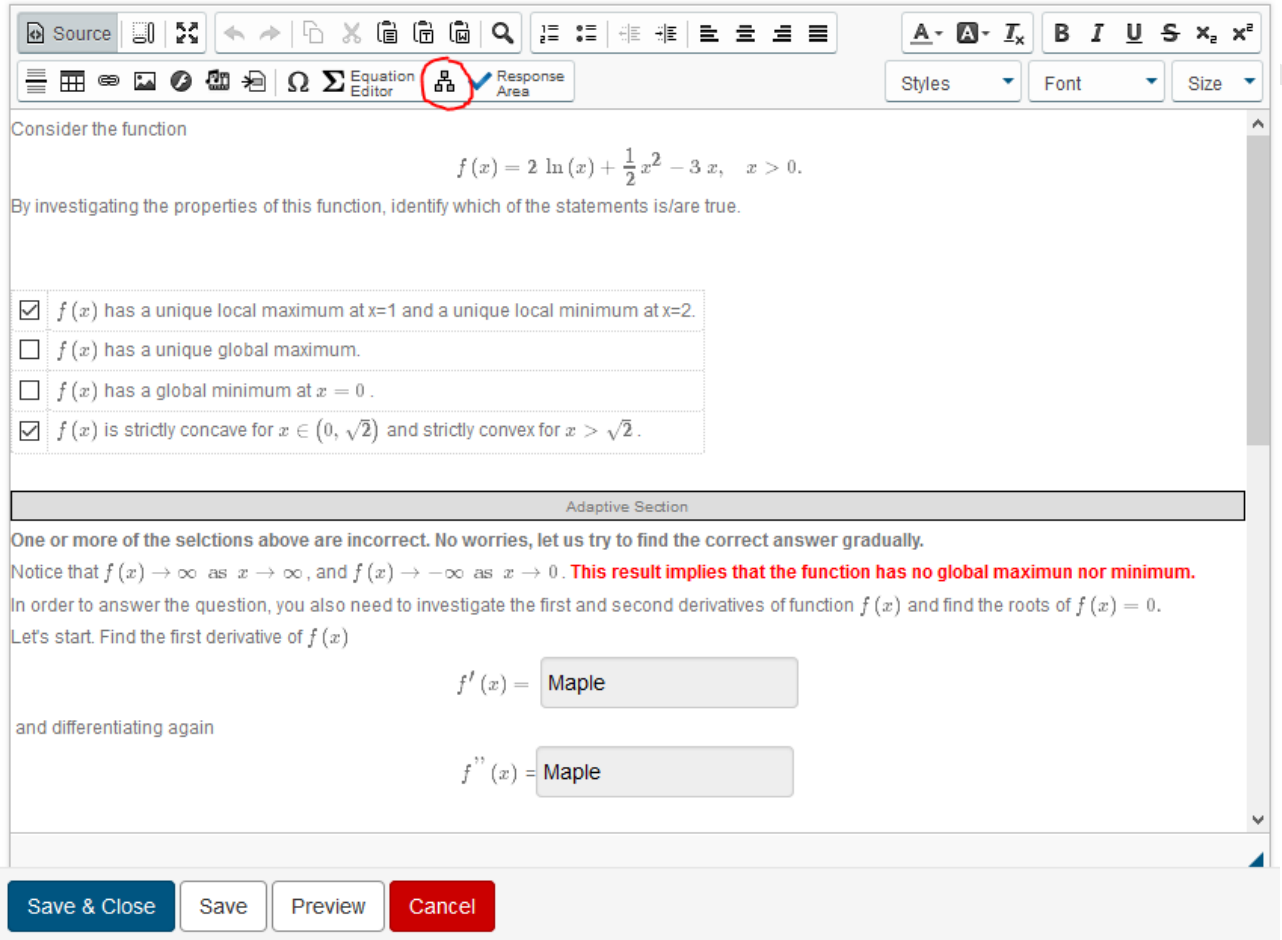

Figure 4: MapleTa question editor with adaptive content.

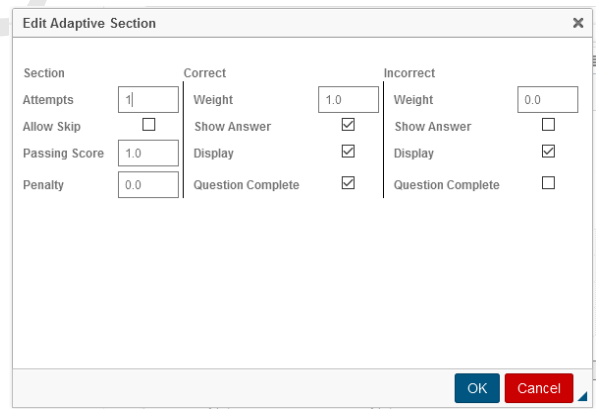

Figure 5: adaptive content options. 
where P represents "price" and Q represents "quantity".

In addition draw the diagram of the marginal revenue function of a monopolist facing demand (1) above.

Finally, draw the diagram of the marginal cost function of this monopolist when costs are given by $C(Q)=2+2.5 Q$.

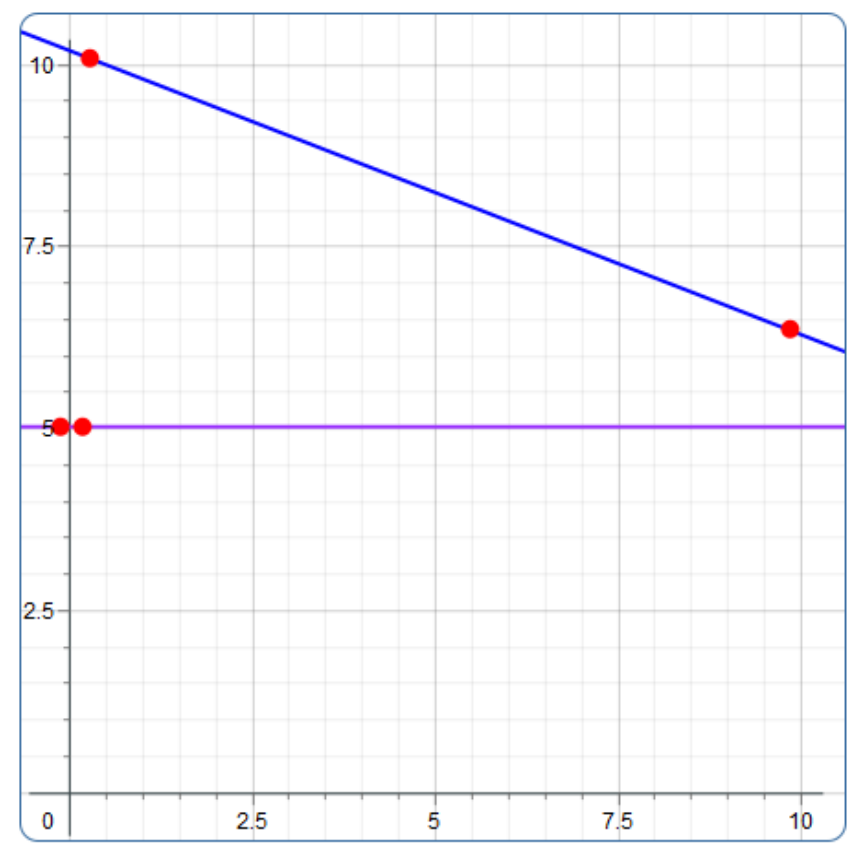

Figure 6: example of incorrect answer submission. 
You did not get it right. No worries! Let us try step-by-step.

Let us start with the demand function

$$
P=10-Q(1)
$$

the function describes a linear relationship between $\mathrm{P}$ and $\mathrm{Q}$.

This relationship, in particular, is negative ( $Q$ is multiplied by -1$)$. Notice, in addition, that if $Q=0$, then $P=10$.

In other words, we know that the demand is a linear function, with intercepts equal to 10 and slope equal to -1 . Try to draw it now.

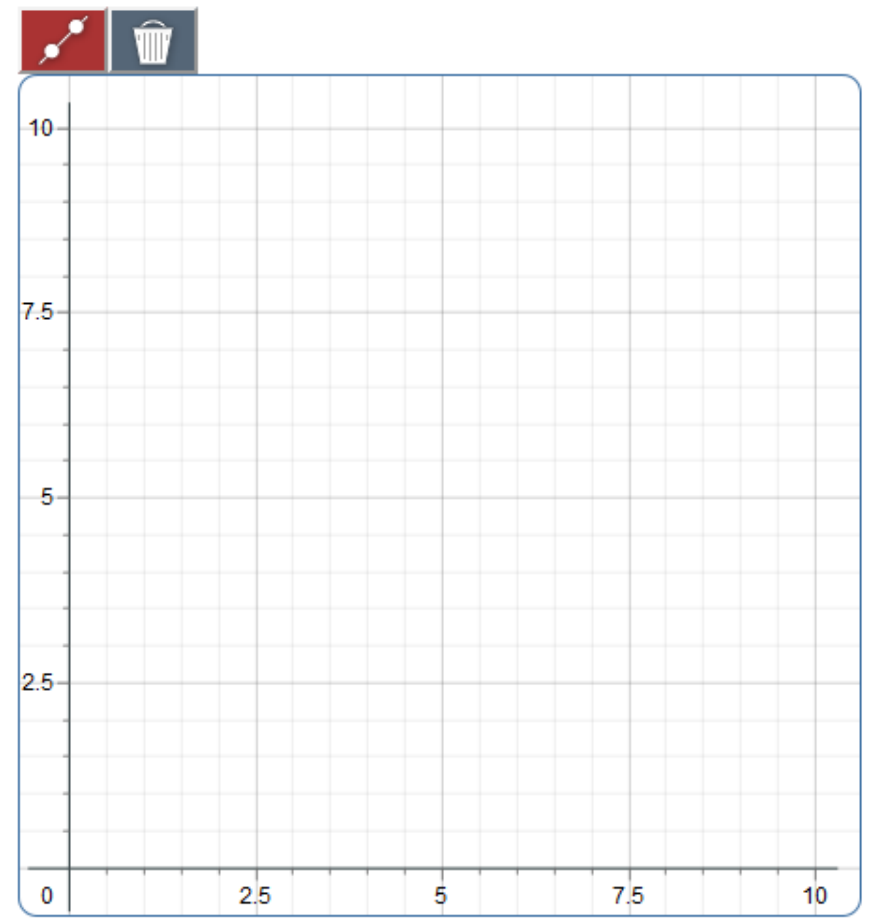

Attempt 1 of $1 \quad$ Verify

Figure 7: adaptive content guiding the student in drawing a linear demand function. 
The marginal revenue function now.

We know that if the inverse demand is linear, the marginal revenue function is also linear, with the same intercept and twice steeper.

This means that the marginal revenue function generated by demand function (1) above is:

MR: $P=10-2 Q$

Try to draw it now.

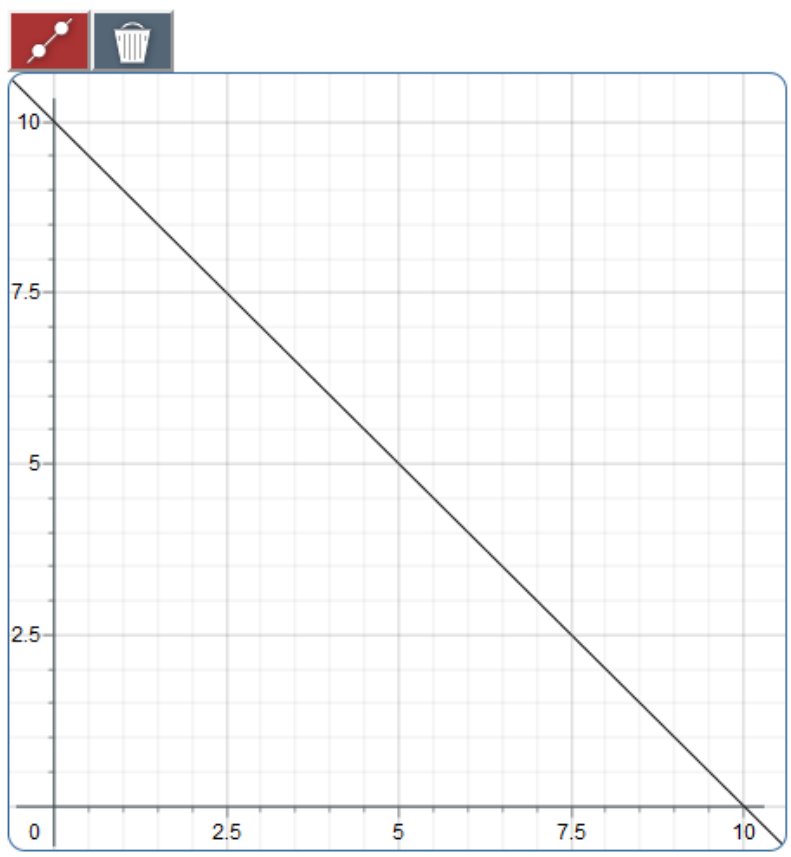

Attempt 1 of $1 \quad$ Verify

Figure 8: adaptive content guiding the student in drawing a marginal revenue function. Notice that the linear demand function found above is already reported. 
Finally, the marginal cost function is given by the first derivative (i.e. the slope) of the cost function with respect to quantity produced. The first derivative of $C(Q)=2+2.5 Q$ with respect to $Q$ is 2.5 . So $M C=2.5$, i.e. an horizontal line passing through 2.5 on the vertical axis. Draw it.

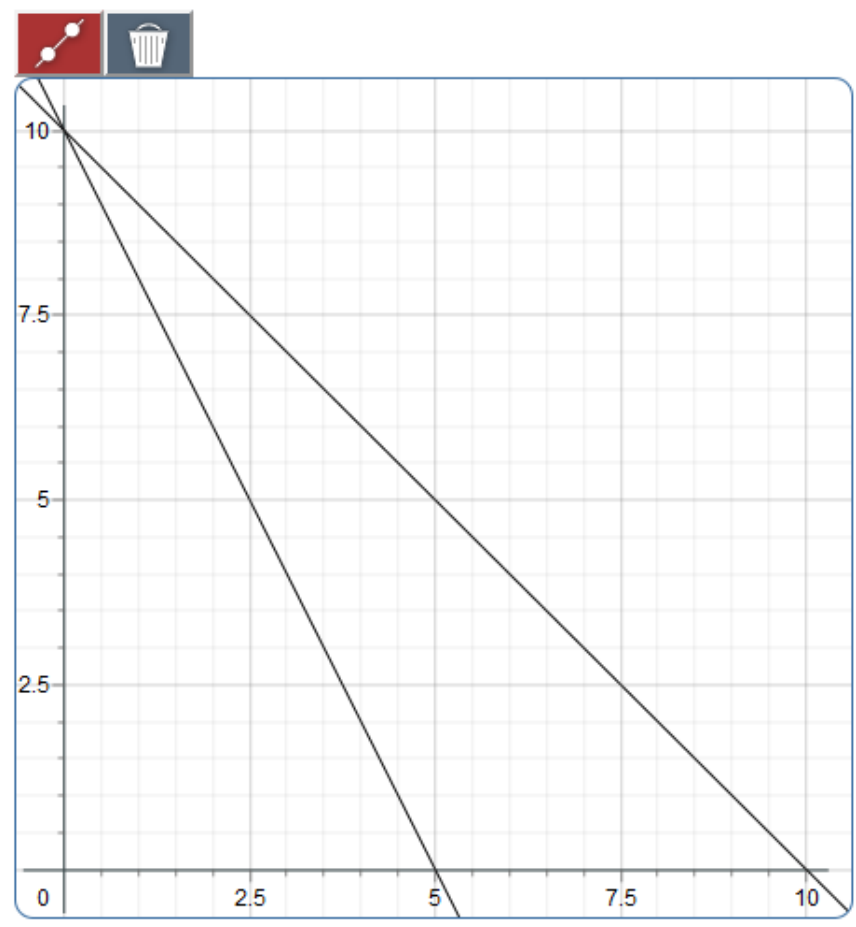

Attempt 1 of $1 \quad$ Verify

Figure 9: adaptive content guiding the student in drawing a marginal cost function. 


\section{Maple T.A.}

Preview

Player 1 and Player 2 play a simultaneous move game and pay-offs are represented in the table below.

Suppose that Player 1 chooses ' $\mathrm{M}$ ".

Whatis the best response of Player 2 ? Click on the correct cell.

\begin{tabular}{cc|c|c|c} 
& & \multicolumn{3}{|c}{ Player 2 } \\
\multirow{3}{*}{ Player 1 } & $L$ & $M$ & $R$ \\
\cline { 2 - 5 } & $T$ & $(100,75)$ & $(120,70)$ & $(140,60)$ \\
\cline { 2 - 5 } & M & $(95,90)$ & $(130,95)$ & $(150,100)$ \\
\hline & $B$ & $(90,110)$ & $(120,120)$ & $(160,110)$
\end{tabular}

Figure 10: 2X2 pay-off matrix of simultanoeus move game. 
Consider now the profit maximisation decision of a monopolist (MR=MC).

In the figure below click on the area that represents the surplus experienced by consumers when price and quantiy is decided by a monopolist

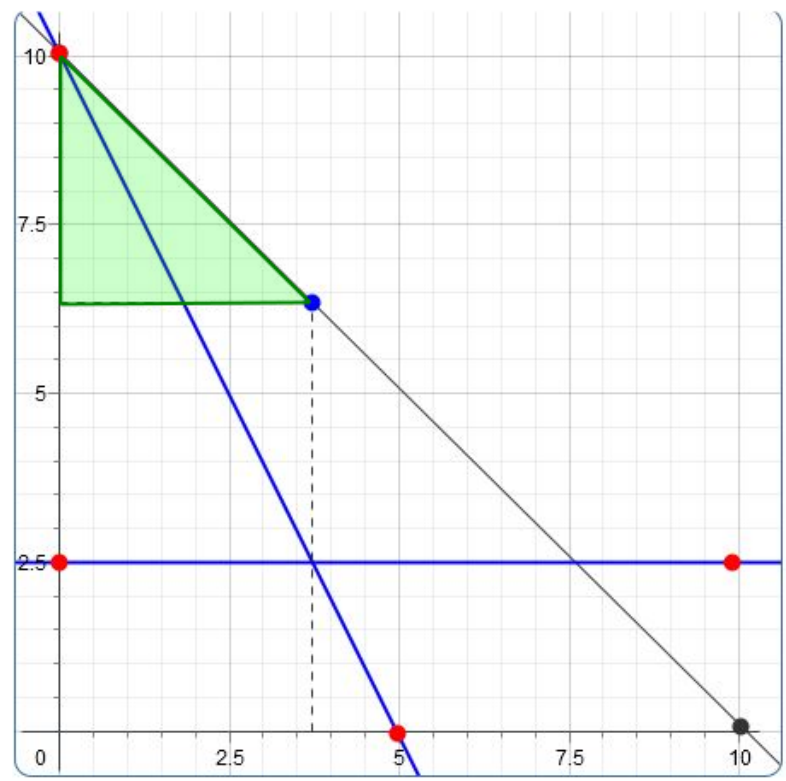

Figure 11: clickable question asking students to indentify consumer surplus. 


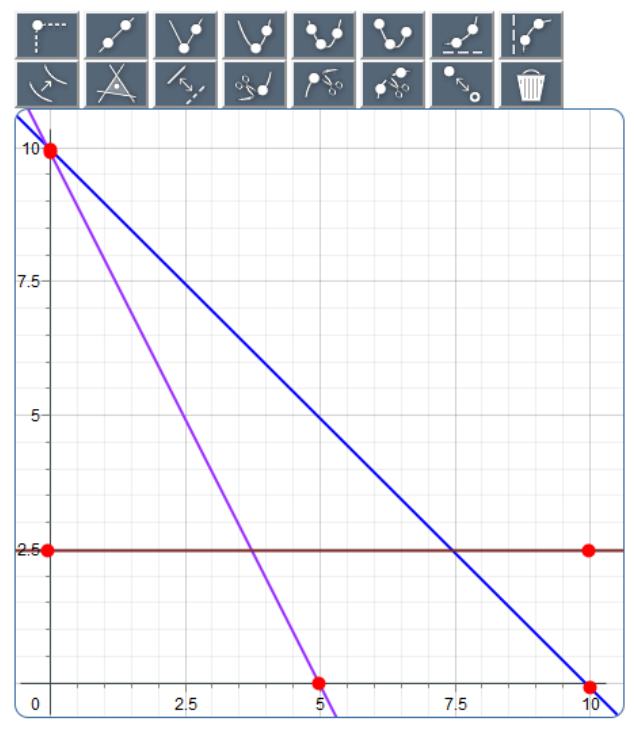

Figure 12: MapleTa toolkit for sketch the graph questions.

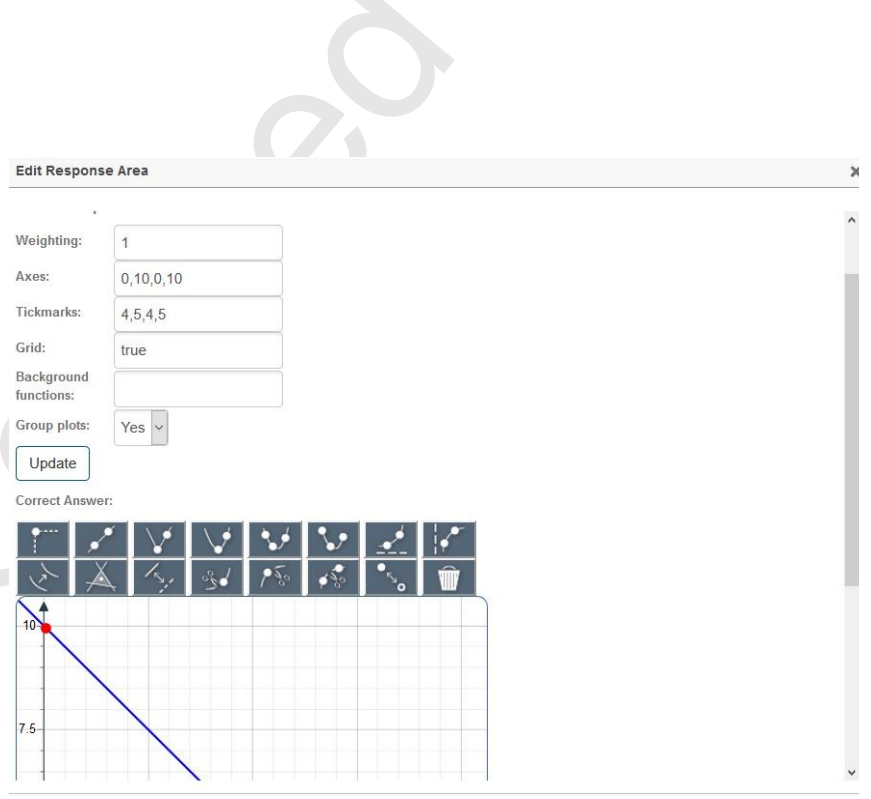

Figure 13: graphical toolkit for instructors. 


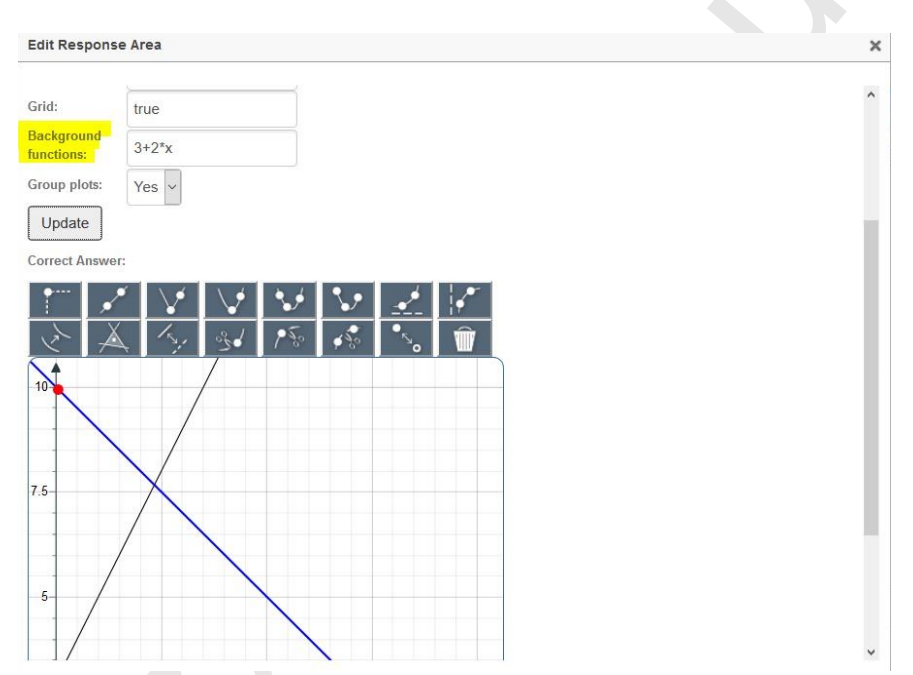

Figure 14: creating diagrams of functions that will appear on the plane when students attempt answering the question. 
On the plane $(P, Q)$ below you can see the diagram of the (inverse) demand function

$$
P=10-Q(1)
$$

where $P$ represents "price" and Q represents "quantity".

Draw the diagram of the marginal revenue function of a monopolist facing demand (1) above.

Finally, draw the diagram of the marginal cost function of this monopolist when costs are given by $C(Q)=2+2.5 Q$.

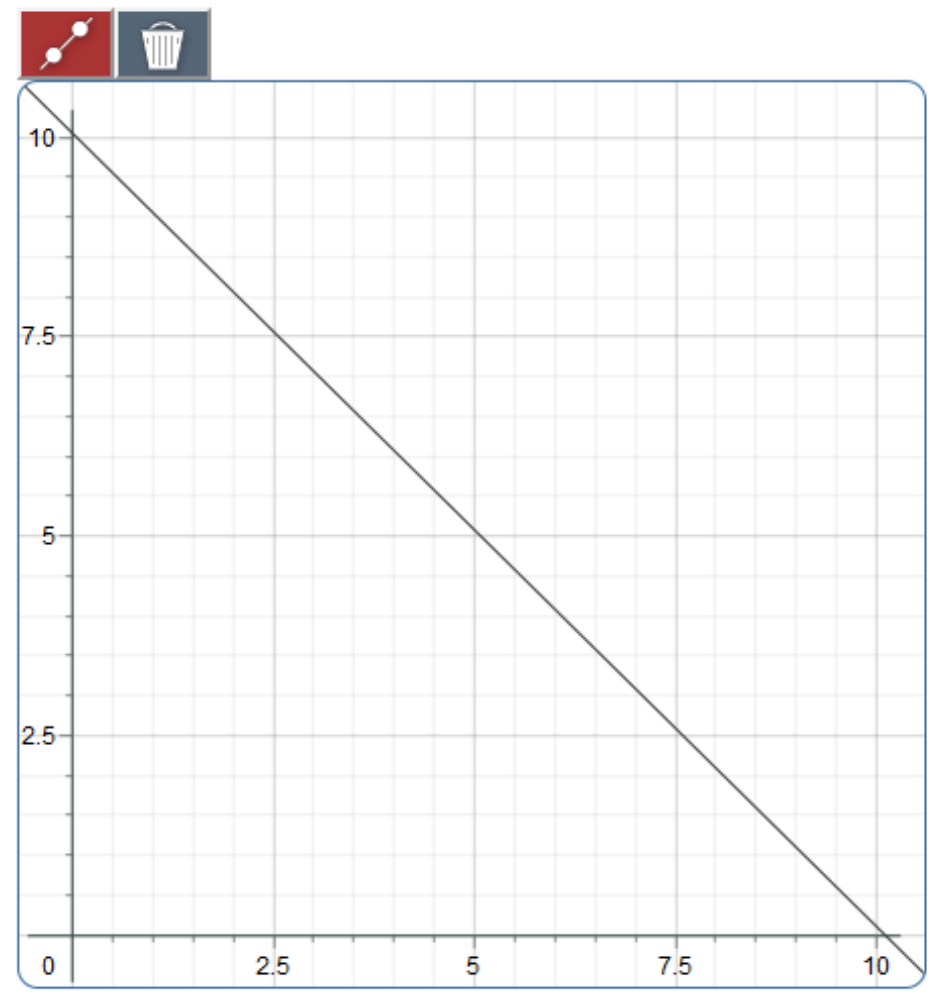

Figure 15: sketch the graph question. 
Consider a market served by two firms, say firm 1 and firm 2. The two firms play a simultaneous move Cournot game and face the following demand: $p=4-\mathrm{q} 1-\mathrm{q} 2$

The cost function of firm 1 is

$C(\mathrm{q} 1)=3 \mathrm{q} 1$ and the cost of firm 2 is

$C(\mathrm{q} 2)=,3 \mathrm{q} 2$

Provide the expressions of the profits of the two firms.

Profit1 $=$

Profit2=

Describe the best response functions of the two firms.

HINT: (i) take the first derivative of Profiti with respect to qi, (ii) set the derivative equal to zero and solve with respect to qi.

$B R 1=\square$ 国国用

$\mathrm{BR} 2=$ 国点居

Figure 16: question asking students to solve a Cournot duopoly. 

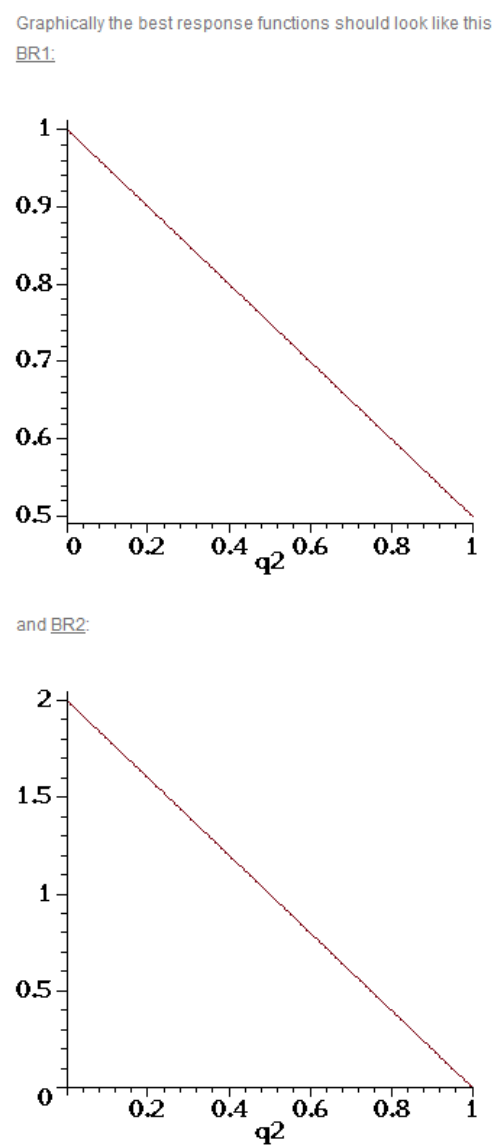

Figure 17: best response functions of the duopoly. 